The journal has had 40 points in Ministry of Education and Science of Poland parametric evaluation. Annex to the announcement of the Minister of Education and Science of December 21, 2021. No. 32343. Has a Journal's Unique Identifier: 201159. Scientific disciplines assigned: Physical Culture Sciences (Field of Medical sciences and health sciences); Health Sciences (Field of Medical Sciences and Health Sciences).

Punkty Ministerialne z 2019 - aktualny rok 40 punktów. Zalącznik do komunikatu Ministra Edukacji i Nauki z dnia 21 grudnia 2021 r. Lp. 32343. Posiada Unikatowy Identyfikator Czasopisma: 201159. Przypisane dyscypliny naukowe:Nauki o kulturze fizycznej (Dziedzina nauk medycznych i nauk o zdrowiu); Nauki o zdrowiu (Dziedzina nauk medycznych i nauk o zdrowiu).

O The Authors 2022;

This article is published with open access at Licensee Open Journal Systems of Nicolaus Copernicus University in Torun, Polan

Open Access. This article is distributed under the terms of the Creative Commons Attribution Noncommercial License which permits any noncommercial use, distribution, and reproduction in any medium, provided the original author (s) and source are credited. This is an open access article licensed under the terms of the Creative Commons Attribution Non commercial license Share alike. The authors declare that there is no conflict of interests regarding the publication of this paper.

Received: 26.01.2022. Revised: 26.01.2022. Accepted: 08.02.2022.

\title{
A family case report of Neurofibromatosis
}

\section{Daniel Wolder}

Department of Gynaecology and Obstetrics, Provincial Integrated Hospital in Kielce https://orcid.org/0000-0001-6418-8725

\section{Adrian Swat}

Department of Gynaecology and Obstetrics, Provincial Integrated Hospital in Kielce https://orcid.org/0000-0001-8817-2621

\begin{abstract}
Neurofibromatosis is a genetic disease inherited in an autosomal, dominant manner. The course of von Recklinghausen's disease varies from patient to patient. Most cases are mild and uncomplicated. The diagnosis of NF1 is based on the criteria of the National Institutes of Health (NIH). Type 2 neurofibromatosis is inherited, in most cases autosomal dominantly. The abnormal allele can be inherited from either parent, with the risk of passing the gene on to the offspring from the parent, being $50 \%$. This article describes the familial form of neurofibromatosis. In the case in question, all three sisters were found to be mutated in the NF1 gene by genetic testing. In the same family, the clinical manifestation of the disease may be different for sisters and children. Due to compliance with medical recommendations, the disease does not significantly affect the quality of life of the families affected.
\end{abstract}

Key words: neurofibromatosis, NF1, NF2, von Recklinghausen's disease 


\section{Introduction}

Neurofibromatosis is a genetic disease inherited in an autosomal, dominant manner. It is characterised by the presence of tumours of the nervous system and skin. There are two main types of this disease - neurofibromatosis type 1 (von Recklinghausen's disease) and type 2 (NF2). Both types differ in the manifestation of clinical symptoms and the frequency of occurrence. Treatment of neurofibromatosis types 1 and 2 includes clinical monitoring and medical intervention, where necessary $[1,2]$.

\section{Neurofibromatosis type 1}

NF-1 is a dominant autosomal disorder. The NF-1 gene is located in chromosome 17 and encodes the protein neurofibromin. Due to the inheritance model, type 1 neurofibromatosis affects all offspring of an afflicted individual. The incidence of NF-1 has been reported to be between 1 in 2,600 to 3,000 people. The incidence is similar in both sexes. Half of the cases are family-related, while the rest are sporadic. The source of sporadic mutations are chromosomes of paternal origin with their risk increasing with the age of the father [3].

The course of von Recklinghausen's disease varies from patient to patient. Most cases are mild and uncomplicated. The differences in manifestation appear to be determined genetically, at least partly. If the clinical picture is confined to one part of the body, it is called segmental NF-1 (neurofibromatosis type 5) due to a mosaic mutation in the NF-1 gene. [3] If the presentation covers the whole body, it is called generalised NF-1. The primary clinical signs are café-au-lait spots, inguinal and/or armpit freckles, Lisch nodules and neurofibromas. Bone dysplasia and optic nerve glioma usually appear at the age of about 1 to 3 years. Cancers, both benign and malignant, occur with increased frequency throughout life [4, 5]. The most common symptoms of neurofibromatosis type 1 are:

- $\quad$ Café-au-lait stains

- $\quad$ Neurofibromas

- Inguinal/armpit freckles

- $\quad$ Lisch nodules

- Neuropsychiatric abnormalities - learning disabilities, cognitive impairment, developmental delay, autism spectrum disorder, macrocephaly

- Malignant neoplasms - optic nerve glioma, neuroblastoma, astrocytoma and brain stem glioma

- $\quad$ IBS

- Hypertension

- $\quad$ Congenital heart defects $[3,6]$.

The diagnosis of NF1 is based on the criteria of the National Institutes of Health (NIH) [7]. Important clinical features of this diagnosis include size and number of café-au-lait freckles and spots, skin neurofibromas, Lisch nodules in the eye and family history. The NIH criteria are both very sensitive and specific, with the exception of young children [8]. A targeted assessment should be carried out together with a developmental assessment. Physical examination should focus on changes in the skin, eyes and the skeletal and nervous systems. It is recommended to examine the eye with a slit lamp. Genetic testing is optional for diagnosis. It can be used in doubtful cases [9]. However, the possibility of a false-negative result, in 
patients with mosaicism, should be taken into account [3]. Due to the diagnostic difficulties related to the late manifestation of clinical symptoms, genetic tests are of great importance in children. This is important because of the various systemic complications and severity of the disease, seen in patients with NF1. Moreover, early diagnosis enables clinicians to plan a systematic evaluation schedule and implement a multidisciplinary approach to management. The treatment includes the drug with a molecular target effect, selumetinib, approved for the treatment of von Recklinghausen's disease in 2020, which inhibits the signalling hyperactivity of MEK1 and MEK2 [10]. As the manifestation of NF1 begins in infancy and progresses with age, education and regular check-ups are important to prevent complications [11].

\section{Neurofibromatosis type 2}

Type 2 neurofibromatosis is inherited, in most cases autosomal dominantly. The abnormal allele can be inherited from either parent, with the risk of passing the gene on to the offspring from the parent, being $50 \%$. Some patients with NF2 have no family history and the disease is then caused by a de novo mutation. The disease is caused by mutations in the NF2 gene, located in the long arm of chromosome 22 (22q12.2). In NF2, it encodes a gene for a protein known as Merlin, also called neurofibromin 2 or Schwannomin. This protein is found in Schwann cells [12]. Bilateral atrial neuromas are a hallmark of NF2 and occur in approximately $90 \%$ to $95 \%$ of patients. These are Schwannomas of the vestibulocochlear nerve, the most common of which are neuromas of the lower branch of the vestibular nerve [13]. Cancer-related symptoms usually appear around the age of 20. Patients usually report tinnitus, sensorineural hearing loss, and balance disturbances. Cutaneous manifestations in NF2 are less common and more subtle than NF1. The most common skin symptom is a lesion resembling plaque. Other skin abnormalities are subcutaneous nodules representing nerve swelling, and skin tumours that generally represent sheath neuromas rather than neurofibromas [14].

The clinical diagnosis of NF2 is based on the presence of one of the following criteria [14]:

- Bilateral vestibular neuromas $(<70$ years of age)

- Unilateral vestibular neuroma before 70 years of age and the first degree relative with NF2

- Two of the following symptoms: meningioma, neurofibroma (non-atrial), neurofibroma, glioblastoma, cerebral calcification, cataract, AND NF2 grade 1 OR

- unilateral atrial neuroma and a negative LZTR1 test result

- Multiple meningiomas and unilateral atrial neuroma or any two of the following: neuroblastoma (non-atrial), neurofibroma, glioma, cerebral calcification, cataract

- Constitutional or mosaic pathogenic mutation of the NF2 gene from the blood, or by identifying an identical mutation from two separate tumours.

Objective

This article describes the familial form of neurofibromatosis. In the case in question, all three sisters were found to be mutated in the NF1 gene by genetic testing. The carrier of this gene was the patients' father. All three patients have children and the course of the pregnancy, the delivery and the clinical status of the children varies.

Neurofibromatosis is an autosomal dominant genetic disorder caused by a mutation in the NF 1 gene, located on the long arm of chromosome 17 (17q11.2). The protein product is neurofibromin, which has a guanosine triphosphatase-activating domain. It contains 60 exons and 350 thousand base pairs, with one of the highest spontaneous mutations in the human genome. In NF1, a mutation of one of the alleles of this gene is inherited, it occurs in all cells 
of the body; the other is spontaneous and occurs in the Schwann cell causing it to proliferate pathologically. It may show high familial clinical variability. In this disease, there is a wide spectrum of CNS symptoms, causing learning disabilities, mental retardation, seizures, attention deficit hyperkinesis, neurofibromas and optic nerve glioma. In the bone-skeletal system, a lateral curvature of the spine is observed. Most often it affects the cervical and thoracic sections. Additionally, these may be accompanied by osteoporosis and osteopenia, deformation of the tibia and fibula that may form pseudo-joints and dysplasia of the sphenoid bone. Changes to the cardiovascular system relate to congenital abnormalities with the most common of these being pulmonary stenosis. Apart from the defects, there is also arterial hypertension and dilatation of the peripheral arteries, including renal arteries, which causes disorders of the urogenital system.

The eldest sister, who is now 37 , has one child. The pregnancy was normal without complications. The physiological birth took place at the age of 28 in the $39^{\text {th }}$ week of gestation. A live- born, mature daughter was reported, weighing $3200 \mathrm{~g}$, measuring $56 \mathrm{~cm}$ and rated at 9 points in the $1^{\text {st }}$. minute of life and 10 points in the $5^{\text {th }}$. minute of life, according to the Apgar Scale.

\section{Physical examination.}

In the patient, the symptoms of the disease concern the skin. There are freckle-like, pigmented lesions all over the body. The greatest intensity occurs in the area of the groin, armpits and neck. Within the abdomen and the back, café-au-lait spots can be observed, constituting flat lesions up to $2-3 \mathrm{~cm}$ in size, with the characteristic colour, 8 . The patient does not exhibit any other changes in the skeletal system, the circulation or the genitourinary system. In the patient's daughter, pigmented skin changes, in the form of freckles in the abdominal skin and around the back, appeared around the age of 3 . There were no café-au-lait stains. There were no changes in any other organs or systems. The baby is developing properly; she attended kindergarten and currently goes to school. There were no pathologies in the form of reduced intellectual abilities, executive functions related to spatial vision or visual-motor integration. In this family, the disease occurs in its mild form and, apart from the inconveniences of an aesthetic nature, does not affect their quality of life.

The other sister, two years younger, is currently 36 years old. She is a mother of two. The woman has freckle-like pigmented lesions all over her body. The highest number of these occurs in and around the armpits and neck. Numerous café-au-lait spots are visible in the abdomen and the back, forming flat foci up to $10-20 \mathrm{~mm}$ in size, with characteristic coloration. In the visual organ, the patient showed pathologies in the form of Lisch nodules. These are nodules of the iris of the hematoma type and consist of pigment cells; mast cells with a structure resembling cutaneous neurofibromatosis. Idiopathic ptosis are also observed. The patient is not currently observing any changes in the skeletal, circulatory and genitourinary systems. She has given birth to two children. The course of the first pregnancy was normal without complications. Physiological delivery took place in the 27 -year-old pregnant woman in the $39^{\text {th }}$. week of pregnancy. Her live-born daughter weighed $3120 \mathrm{~g}$ and measured $53 \mathrm{~cm}$; she rated at 10 points in the $1^{\text {st }}$. minute of life and 10 points in the $5^{\text {th }}$. minute of life, according to the Apgar Scale. In the 9-year-old girl, pigmented lesions resembling freckles, affect the entire body. In the $5^{\text {th }}$. year of life, epileptic seizures of the tonic-clonic and partially complex type, occurred. These are most likely an expression of impaired myelination that can be found on magnetic resonance imaging. These changes may disappear in adult life. The child attended kindergarten. The child was diagnosed with motor hyperactivity syndrome, decreased intellectual abilities, impaired executive function, spatial vision and visual-motor integration. This is due to the overactivity of the Ras protein causing disturbances in 
GABAergic transmission. The course of the second pregnancy in the 29-year-old patient was abnormal. The patient was hospitalised due to imminent miscarriage and premature delivery. Pregnancy was terminated by Caesarean section at 37 weeks of gestation, after premature drainage of amniotic fluid and foetal hypotrophy. Her live-born son weighed $2180 \mathrm{~g}$, measured $49 \mathrm{~cm}$, rated at 9 points in the $1^{\text {st }}$. minute of life and 10 points in the $5^{\text {th }}$. minute of life, according to the Apgar Scale. Due to his low birth weight, the child was under the supervision of the Newborn Pathology Clinic for the first year of life. He is developing properly; no changes in the skin and other organs and systems have been found. In this family, the disease occurs in a complex form and, apart from the inconveniences of an aesthetic nature, requires control and does not affect their quality of life.

The third sister, 32 years of age, is a mother of three. The woman has freckle-like pigmented lesions all over her body. There are numerous café-au-lait spots around the abdomen, the dorsum and the limbs, which are flat foci, up to $10-20 \mathrm{~mm}$ in size, with a characteristic colour. The patient has subcutaneous neurofibromas, found during palpation examination. They are manifested by tenderness and tingling along the path of the affected nerve. Sometimes there are sensory and motor deficits along the occupied nerve. In the skeletal system, a lateral curvature of the spine is visible in the thoracic section of 45 degrees, with developing osteoporosis and osteopenia. Deformities of the tibia and fibula are observed. There were no pathological fractures or the formation of pseudo-joints. In the visual organ, as with the sisters', pathologies in the form of Lisch's nodules were visualised. The patient does not follow medical recommendations. Scoliosis requires the wearing of a corset and corrective surgery leading to the surgical fusion of the vertebrae. The patient does not wear a corset and has not undergone surgical correction despite recommendations.

The course of all three pregnancies was pathological. Firstly, the pregnancy at the age of 23 . The patient was hospitalised several times due to imminent miscarriage, premature delivery, gestational diabetes and foetal hypotrophy. Due to bone changes and the patient's clinical condition, the first pregnancy was delivered by Caesarean section in the $37^{\text {th }}$. week of gestation. The daughter, live-born, albeit prematurely, weighed $2230 \mathrm{~g}$, measured $48 \mathrm{~cm}$ and was rated at 9 points in the $1^{\text {st }}$. minute of life and 10 points in $5^{\text {th }}$. minute of life, according to Apgar Scale. Due to her low birth weight, the child was under the supervision of the Newborn Pathology Clinic for the first year of life. In the 9-year-old girl, pigmented lesions, resembling freckles, affect the entire body. At the age of 3, optic nerve glioma occupying the visual pathways was diagnosed in the central nervous system. Due to diagnostic difficulties, since a small child is unable to communicate changes in visual acuity and visual field, a fundus examination was performed to look for changes in the optic nerve disc. The study was confirmed in imaging studies. Surgery, to remove the tumour, was performed in the Children's Health Centre (CZD), followed by chemotherapy. The child did not attend kindergarten. The child was diagnosed with motor hyperactivity syndrome, decreased intellectual abilities, impaired executive function, spatial vision and visual-motor integration. The course of the second pregnancy, at the age of 28 was also irregular. The patient was hospitalised several times due to imminent pre-term labour, dietary diabetes in pregnancy, foetal hypotrophy, skeletal bone changes and her post-Caesarean section condition. Due to the clinical condition of the patient, related to her von Recklinghausen's disease condition, post-Caesarean section, a decision was made to perform a Caesarean section in the $36^{\text {th }}$. week of pregnancy. Her daughter, prematurely born, weighed $2180 \mathrm{~g}$, measured $48 \mathrm{~cm}$ and was rated at 9 points in the $1^{\text {st }}$. minute of life and 10 points in the $5^{\text {th }}$. minute of life, according to the Apgar Scale. Due to the low birth weight, the child was also under the control of the Newborn Pathology Clinic for the first year of life. Pigmented skin changes, in the form of freckles all over the body, appeared in the patient's daughter between 2-3 years of age. There were no café-au-lait stains. 
The baby is developing properly. There is no evidence of any impairment to intellectual ability or visual-motor integration. She does not go to kindergarten. The course of the third pregnancy at the age of 30 was also irregular. The patient was hospitalised several times due to PPI, GDM. Due to the patient's clinical condition, after two Caesarean sections, a decision was made to perform a Caesarean section in the $38^{\text {th }}$. week of pregnancy. Her prematurelyborn son, weighed $2800 \mathrm{~g}$, measured $51 \mathrm{~cm}$ and was rated at 9 points in the $1^{\text {st }}$. minute of life and 10 points in the $5^{\text {th }}$. minute of life, according to the Apgar Scale. Due to the mother's disease, the child was also under the control of the Newborn Pathology Clinic for the first year of life. The two-year-old boy without skin lesions is developing normally.

\section{Discussion}

NF1 is a genetically determined, autosomal disease caused by a mutation in the NF1 gene, located on chromosome 17 (17q11.2). Many authors argue that the neoplastic cell in this disease is a Schwann cell, which inactivates both alleles of the NF1 gene. In NF1, one of the alleles of the gene is inherited in all cells of the body, the other is in the Schwann cell, causing it to proliferate pathologically. NF1 exhibits high individual and familial variability. In the cases presented, there is a large individual variability regarding skin lesions, a broad spectrum from the CNS or the osteoarticular system. The diagnosis of NF1 is based on two or more of the following clinical features: café-au-lait spots, more than 6 in number, with a diameter greater than $5 \mathrm{~mm}$, armpit or inguinal freckles, minimum 2 neurofibromas of any type, a minimum of 2 Lisch nodules, optic nerve glioblastoma and skeletal anomalies. The incidence of peripheral and cerebral vascular lesions, in children with NF1, ranges from $1 \%$ to $8 \%$ in asymptomatic children. Arterial and venous vessels may be involved in the form of: aneurysm, pseudoaneurysm, fistulas, ectasia, narrowing, and ruptures. Developing knowledge gives a chance to introduce targeted treatment of this phacomatosis. In animal experiments, it was shown that the presence of heterozygous cells /(NF1 +/-) mainly mast cells and fibroblasts, stimulates the development of neurofibromas. Schwann cells NF1 -/- secrete chemotactic agents such as ligand KIT, causing increased influx and activation of mast cells NF1+/-, which produce mitogens, increasing the proliferation of Schwann cells and transforming growth factor (TGF- $\beta$ ) which causes an increased production of collagen. The same is true for CNS tumours. NF1astrocytes -/- require stimulation by substances secreted by neurons and endothelial cells, in order to proliferate. These include CXCL12 chemokine. The appearance of more intense changes during puberty or pregnancy, indicates the participation of sex hormones in promoting the development of neoplasms in NF1. In INF1 tumours, activation of ERK and AKT kinases, mTOR related to various types of intracellular transmission pathways was found $[1,2]$.

\section{Conclusions}

1. NF-1 is a dominant autosomal disorder. The NF-1 gene is located on chromosome 17 and encodes the protein neurofibromin.

2. Due to the inheritance model, type 1 neurofibromatosis affects all offspring of the individual affected.

3. In the same family, the clinical manifestation of the disease may be different for sisters and children.

4. Due to compliance with medical recommendations, the disease does not significantly affect the quality of life of the families affected.

\section{References}


1. Le C, Bedocs PM. Neurofibromatosis. 2021 Oct 9. In: StatPearls [Internet]. Treasure Island (FL): StatPearls Publishing; 2021 Jan-. PMID: 29083784.

2. Ghalayani P, Saberi Z, Sardari F. Neurofibromatosis type I (von Recklinghausen's disease): A family case report and literature review. Dent Res J (Isfahan). 2012 Jul;9(4):483-8. [PMC free article] [PubMed] [Reference list]

3. Adil A, Koritala T, Singh AK. Neurofibromatosis Type 1. 2021 Sep 17. In: StatPearls [Internet]. Treasure Island (FL): StatPearls Publishing; 2021 Jan-. PMID: 29083628.

4. Seminog OO, Goldacre MJ. Risk of benign tumours of nervous system, and of malignant neoplasms, in people with neurofibromatosis: population-based record-linkage study. Br J Cancer. 2013 Jan 15;108(1):193-8. [PMC free article] [PubMed] [Reference list]

5. Gürsoy S, Erçal D. Genetic Evaluation of Common Neurocutaneous Syndromes. Pediatr Neurol. 2018 Dec;89:3-10. [PubMed] [Reference list]

6. Lorenzo J, Barton B, Arnold SS, North KN. Developmental trajectories of young children with neurofibromatosis type 1: a longitudinal study from 21 to 40 months of age. J Pediatr. 2015 Apr;166(4):1006-12.e1. [PubMed] [Reference list]

7. National Institutes of Health Consensus Development Conference Statement: neurofibromatosis. Bethesda, Md., USA, July 13-15, 1987.

8. DeBella K, Szudek J, Friedman JM. Use of the national institutes of health criteria for diagnosis of neurofibromatosis 1 in children. Pediatrics. 2000 Mar;105(3 Pt 1):608-14. [PubMed] [Reference list]

9. Messiaen LM, Callens T, Mortier G, Beysen D, Vandenbroucke I, Van Roy N, Speleman F, Paepe AD. Exhaustive mutation analysis of the NF1 gene allows identification of $95 \%$ of mutations and reveals a high frequency of unusual splicing defects. Hum Mutat. 2000;15(6):541-55. [PubMed] [Reference list]

10. Kim YM. Improving the lives of children with neurofibromatosis type 1. Clin Exp Pediatr. 2021 Apr;64(4):165-166. doi: 10.3345/cep.2020.01277. Epub 2020 Sep 18. PMID: 32972053; PMCID: PMC8024116.

11. Kang E, Yoon HM, Lee BH. Neurofibromatosis type I: points to be considered by general pediatricians. Clin Exp Pediatr. 2021 Apr;64(4):149-156. doi: 10.3345/cep.2020.00871. Epub 2020 Jul 15. PMID: 32683805; PMCID: PMC8024119.

12. Tiwari R, Singh AK. Neurofibromatosis Type 2. 2021 Oct 9. In: StatPearls [Internet]. Treasure Island (FL): StatPearls Publishing; 2021 Jan-. PMID: 29261934.

13. Wippold FJ, Lubner M, Perrin RJ, Lämmle M, Perry A. Neuropathology for the neuroradiologist: Antoni A and Antoni B tissue patterns. AJNR Am J Neuroradiol. 2007 Oct;28(9):1633-8. [PMC free article] [PubMed] [Reference list]

14. Smith MJ, Bowers NL, Bulman M, Gokhale C, Wallace AJ, King AT, Lloyd SK, Rutherford SA, Hammerbeck-Ward CL, Freeman SR, Evans DG. Revisiting neurofibromatosis type 2 diagnostic criteria to exclude LZTR1-related schwannomatosis. Neurology. 2017 Jan 03;88(1):87-92. [PMC free article] [PubMed] [Reference list]

15. Mautner VF, Nguyen R, Kutta H, Fuensterer C, Bokemeyer C, Hagel C, Friedrich RE, Panse J. Bevacizumab induces regression of vestibular schwannomas in patients with 
neurofibromatosis type 2. Neuro Oncol. 2010 Jan;12(1):14-8. [PMC free article] [PubMed] [Reference list] 